ARTICLE

DOI: $10.1038 / s 41467-018-05758-5$

\title{
High-performance artificial nitrogen fixation at ambient conditions using a metal-free electrocatalyst
}

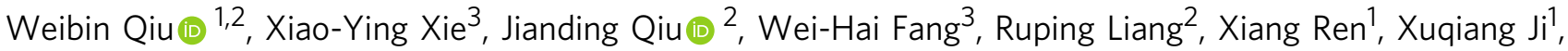 \\ Guanwei Cuii ${ }^{4}$ Abdullah M. Asiri (1) ${ }^{5}$, Ganglong Cui ${ }^{3}$, Bo Tang ${ }^{4} \&$ Xuping Sun (1) ${ }^{1}$
}

Conversion of naturally abundant nitrogen to ammonia is a key (bio)chemical process to sustain life and represents a major challenge in chemistry and biology. Electrochemical reduction is emerging as a sustainable strategy for artificial nitrogen fixation at ambient conditions by tackling the hydrogen- and energy-intensive operations of the Haber-Bosch process. However, it is severely challenged by nitrogen activation and requires efficient catalysts for the nitrogen reduction reaction. Here we report that a boron carbide nanosheet acts as a metal-free catalyst for high-performance electrochemical nitrogen-to-ammonia fixation at ambient conditions. The catalyst can achieve a high ammonia yield of $26.57 \mu \mathrm{g} \mathrm{h}^{-1}$ $\mathrm{mg}^{-1}$ cat. and a fairly high Faradaic efficiency of $15.95 \%$ at $-0.75 \mathrm{~V}$ versus reversible hydrogen electrode, placing it among the most active aqueous-based nitrogen reduction reaction electrocatalysts. Notably, it also shows high electrochemical stability and excellent selectivity. The catalytic mechanism is assessed using density functional theory calculations.

\footnotetext{
${ }^{1}$ Institute of Fundamental and Frontier Sciences, University of Electronic Science and Technology of China, Chengdu 610054 Sichuan, China. ${ }^{2}$ College of Chemistry, Nanchang University, Nanchang 330031 Jiangxi, China. ${ }^{3}$ Key Laboratory of Theoretical and Computational Photochemistry, Ministry of Education, College of Chemistry, Beijing Normal University, Beijing 100875, China. ${ }^{4}$ College of Chemistry, Chemical Engineering and Materials Science, Shandong Normal University, Jinan 250014 Shandong, China. ${ }^{5}$ Chemistry Department, Faculty of Science and Center of Excellence for Advanced Materials Research, King Abdulaziz University, P.O. Box 80203 Jeddah 21589, Saudi Arabia. These authors contributed equally: Weibin Qiu, Xiao-Ying Xie. Correspondence and requests for materials should be addressed to G.C. (email: ganglong.cui@bnu.edu.cn) or to B.T. (email: tangb@sdnu.edu.cn) or to X.S. (email: xpsun@uestc.edu.cn)
} 
A mmonia $\left(\mathrm{NH}_{3}\right)$ is an essential building block for manufacturing synthetic chemicals, such as fertilizers, medicaments, dyes, explosives, and resins ${ }^{1-3} \cdot \mathrm{NH}_{3}$ has also received attention as an alternative energy carrier to advance a low-carbon society due to its large hydrogen capacity (17.6 wt\%) and high energy density $\left(4.3 \mathrm{kWh} \mathrm{h}^{-1}\right)^{4}$. The ever-increasing demand for $\mathrm{NH}_{3}$ has stimulated significant research interest in artificial nitrogen $\left(\mathrm{N}_{2}\right)$ fixation ${ }^{5-13}$. Currently, industrial-scale $\mathrm{NH}_{3}$ production mainly relies on the Haber-Bosch process at high temperature and pressure using $\mathrm{N}_{2}$ and hydrogen $\left(\mathrm{H}_{2}\right)$ as feed gases ${ }^{14-16}$. However, this process accounts for $\sim 2 \%$ of the worldwide energy use, i.e., $34 \mathrm{GJ} \operatorname{ton}_{\mathrm{NH} 3}{ }^{-1}$ and produces a large amount of $\mathrm{CO}_{2}\left(\sim 2 \text { ton }_{\mathrm{CO} 2} \operatorname{ton}_{\mathrm{NH} 3}{ }^{-1}\right)^{17,18}$. In this regard, it is highly imperative to develop lower-energy $\mathrm{N}_{2}$-fixation methods, ideally operating at low temperature and pressure.

Biological $\mathrm{N}_{2}$ fixation is catalyzed by nitrogenase at ambient conditions through multiple proton and electron transfer steps, requiring a significant energy input delivered by adenosine triphosphate (ATP) ${ }^{11,19-21}$. Encouragingly, electrochemical $\mathrm{N}_{2}$ reduction using protons and electrons can be powered by renewable energy from solar or wind sources, offering a promising environmentally benign process for sustainable artificial $\mathrm{N}_{2}$ fixation at room temperature and pressure ${ }^{22,23}$. This process, however, is severely challenged by $\mathrm{N}_{2}$ activation and demands efficient catalysts for the $\mathrm{N}_{2}$ reduction reaction (NRR) ${ }^{24-26}$. NRR catalysts based on noble metals (e.g., $\mathrm{Au}^{27,28}, \mathrm{Ru}^{29}, \mathrm{Rh}^{30}$ ) show favorable activity, but widespread use is hindered by scarcity and high cost. Much attention has thus focused on designing and developing non-noble-metal alternatives but with low Faradaic efficiency (FE), including $\mathrm{Fe}_{2} \mathrm{O}_{3}-\mathrm{CNT}^{31}, \mathrm{Fe}_{3} \mathrm{O}_{4}{ }^{32}, \mathrm{Li}^{+}$-incorporated $\mathrm{PEBCD} / \mathrm{C}^{33}, \mathrm{MoS}_{2}{ }^{34}$, (110)-oriented Mo nanofilm ${ }^{35}$, $\mathrm{MoO}_{3}{ }^{36}, \mathrm{Mo}_{2} \mathrm{~N}^{37}$, etc. Recently, Lv et al. have reported improved NRR catalytic performance in an amorphous $\mathrm{Bi}_{4} \mathrm{~V}_{2} \mathrm{O}_{11}$-crystalline $\mathrm{CeO}_{2}$ hybrid (BVC-A) with a high $\mathrm{FE}$ of $10.16 \%$ and a $\mathrm{NH}_{3}$ yield that can reach up to $23.21 \mu \mathrm{g} \mathrm{h}^{-1} \mathrm{mg}^{-1}$ cat. (ref. ${ }^{38}$ ). Compared with the catalysts above, metal-free materials offer an obvious advantage of avoiding metal ion release, thereby reducing the environmental impact. $\mathrm{N}$-doped nanocarbon was recently reported for $\mathrm{N}_{2}$ reduction electrocatalysis with a remarkable $\mathrm{NH}_{3}$ yield of $23.8 \mu \mathrm{g} \mathrm{h}^{-1} \mathrm{mg}^{-1}$ cat. , but its FE is only $1.42 \%{ }^{39}$. In this context, the idenfication of new metal-free NRR nanocatalysts that simultaneously achieve high $\mathrm{NH}_{3}$ formation rate and $\mathrm{FE}$ is highly desired, which, however, still remains a key challenge.

Boron carbide $\left(\mathrm{B}_{4} \mathrm{C}\right)$, one of the hardest materials in nature next to diamond and cubic boron nitride, possesses high mechanical strength, (electro)chemical stability, and good electronic conductivity, and much attention has focused on its electrochemical uses as electrode material or catalyst substrate for batteries and fuel cells ${ }^{40-43}$. Here we report our recent finding that $\mathrm{B}_{4} \mathrm{C}$ nanosheet behaves as a superb metal-free electrocatalyst toward artificial $\mathrm{N}_{2}$ fixation with excellent selectivity for $\mathrm{NH}_{3}$ formation under ambient conditions. In $0.1 \mathrm{M}$ hydrochloric acid $(\mathrm{HCl})$, it is capable of achieving an average $\mathrm{NH}_{3}$ formation rate and a FE as high as $26.57 \mu \mathrm{g} \mathrm{h}^{-1} \mathrm{mg}^{-1}$ cat. and $15.95 \%$ at $-0.75 \mathrm{~V}$, respectively, placing it among the most active aqueous-based NRR electrocatalysts. Notably, it also shows high electrochemical stability. In $0.1 \mathrm{M}$ sodium sulfate $\left(\mathrm{Na}_{2} \mathrm{SO}_{4}\right)$, the catalyst still exhibits good activity and selectivity with an $\mathrm{NH}_{3}$ yield of $14.70 \mu \mathrm{g} \mathrm{h}^{-1} \mathrm{mg}^{-1}$ cat. and a FE of $9.24 \%$. Density functional theory (DFT) calculations suggest that the ${ }^{\star} \mathrm{NH}_{2}-{ }^{\star} \mathrm{NH}_{2} \rightarrow{ }^{*} \mathrm{NH}_{2}{ }^{*} \mathrm{NH}_{3}$ reaction is the rate-limiting step.

\section{Results}

Synthesis and characterization of boron carbide nanosheet. The $\mathrm{B}_{4} \mathrm{C}$ nanosheet was produced by liquid exfoliation of bulk
$\mathrm{B}_{4} \mathrm{C}$ (see Methods for preparation details). As shown in Fig. 1a, the X-ray diffraction (XRD) pattern for $\mathrm{B}_{4} \mathrm{C}$ is highly crystalline with diffraction peaks at $19.7^{\circ}, 22.0^{\circ}, 23.5^{\circ}, 31.9^{\circ}, 34.9^{\circ}, 37.8^{\circ}$, $53.5^{\circ}, 63.7^{\circ}$, and $66.7^{\circ}$ that are indexed to the (101), (003), (012), (110), (104), (021), (205), (125), and (220) planes of $\mathrm{B}_{4} \mathrm{C}$ phase (JCPDS No. 35-0798) ${ }^{44}$, respectively. Further characterization by scanning electron microscopy (SEM) and transmission electron microscopy (TEM) confirm the formation of nanosheets after liquid exfoliation, as shown in Supplementary Fig. 1 and Fig. 1b. The higher magnification TEM image (Fig. 1c) reveals the formation of few-layered $\mathrm{B}_{4} \mathrm{C}$ nanosheet. The high-resolution TEM (HRTEM) image (Fig. 1d) of such a nanosheet shows wellresolved lattice fringes with an interplanar distance of $0.280 \mathrm{~nm}$ indexed to the (110) plane of $\mathrm{B}_{4} \mathrm{C}$. The corresponding selected area electron diffraction (SAED) pattern (Fig. 1e) shows welldefined rings indexed to the (012), (110), and (104) planes of $\mathrm{B}_{4} \mathrm{C}$. $\mathrm{X}$-ray photoelectron spectroscopy (XPS) spectra of $\mathrm{B}_{4} \mathrm{C}$ in $\mathrm{C} 1 \mathrm{~s}$ (Fig. 1f) and B 1s (Fig. 1g) regions are in good agreement with reported results ${ }^{45}$. The peaks in $\mathrm{B} 1 s$ are $187.5 \mathrm{eV}$ and $189.1 \mathrm{eV}$, which can be associated with the $\mathrm{B}$ atoms in $\mathrm{B}-\mathrm{B}$ and $\mathrm{B}-\mathrm{C}$ bonds, respectively. The peaks of $\mathrm{C} 1 s$ spectrum are $284.6 \mathrm{eV}(\mathrm{C}$ $-\mathrm{C}$ bond), $286.2 \mathrm{eV}$ ( $\mathrm{C}-\mathrm{O}$ bond) and $281.8 \mathrm{eV}$ ( $\mathrm{C}-\mathrm{B}$ bond). The Raman spectroscopy of the $\mathrm{B}_{4} \mathrm{C}$ presents characteristic Raman peaks at $270,320,481,531,728,830,1000$, and $1088 \mathrm{~cm}^{-1}$ assigned to crystalline $\mathrm{B}_{4} \mathrm{C}$ (Supplementary Fig. 2) ${ }^{46}$.

Electrocatalytic nitrogen reduction performance. The NRR catalytic performance is examined at controllable applied voltages using a three-electrode system comprising of a graphite rod as a counter electrode, $\mathrm{Ag} / \mathrm{AgCl}$ as a reference electrode and $\mathrm{a}_{4} \mathrm{C}$ nanosheet-loaded carbon paper electrode (CPE) as a working electrode $\left(\mathrm{B}_{4} \mathrm{C} / \mathrm{CPE} ; \mathrm{B}_{4} \mathrm{C}\right.$ nanosheet loading: $\left.0.1 \mathrm{mg} \mathrm{cm}^{-2}\right)$. During electrolysis, $\mathrm{N}_{2}$ gas is bubbled into the cathode, where protons transported from the electrolyte $(0.1 \mathrm{M} \mathrm{HCl}$ aqueous solution) can react with $\mathrm{N}_{2}$ on the surface of the catalyst to produce $\mathrm{NH}_{3}$. As shown in Fig. 2a, the current of chronoamperometry curves at different potentials exert good stability. The current density starts high and then decreases to a steady state, which might be ascribed to double layer charging and a result of decreasing local concentration of $\mathrm{H}^{+}$and $\mathrm{N}_{2}$ near the electrode surface ${ }^{47}$.

To confirm the successful $\mathrm{N}_{2}$ electroreduction in $0.1 \mathrm{M} \mathrm{HCl}$, the production of both $\mathrm{NH}_{3}$ and a possible by-product hydrazine $\left(\mathrm{N}_{2} \mathrm{H}_{4}\right)$ are spectrophotometrically evaluated after 2 -h electrolysis operation by the indophenol blue $\operatorname{method}^{7}$ and the method of Watt and Chrisp ${ }^{48}$, respectively (the corresponding calibration curves are shown in Supplementary Fig. 3-4). Figure 2b shows the UV-Vis absorption spectra of electrolyte colored with indophenol indicator at a series of potentials under $\mathrm{N}_{2}$ bubbling. This detection of $\mathrm{NH}_{3}$ is concrete and unambiguous proof of $\mathrm{NH}_{3}$ formation via the electroreduction of $\mathrm{N}_{2}$ in our $\mathrm{B}_{4} \mathrm{C} / \mathrm{CPE}$ platform at potential ranges from $-0.65 \mathrm{~V}$ to $-1.05 \mathrm{~V}$.

The average $\mathrm{NH}_{3}$ yields and corresponding FEs were determined to exemplify the $\mathrm{B}_{4} \mathrm{C}$ nanosheet as an efficient catalyst for the fixation of inert $\mathrm{N}_{2}$ molecules into highly valuable $\mathrm{NH}_{3}$ (Fig. 2c). As observed, $\mathrm{NH}_{3}$ yields increase with more negative potential until reaching $-0.75 \mathrm{~V}$, where the maximum value of $\mathrm{NH}_{3}$ yield is calculated as $26.57 \mu \mathrm{g} \mathrm{h}^{-1} \mathrm{mg}^{-1}$ cat. with a FE of $15.95 \%$, outperforming most reported aqueous-based NRR catalysts at ambient conditions (Supplementary Table 1). The $\mathrm{NH}_{3}$ yield and FE of NRR increase initially $(-0.65 \mathrm{~V}$ to $-0.75 \mathrm{~V})$ and then start to decrease as the potential is negatively shifted to $-1.05 \mathrm{~V}$, which is attributed to the FE of the hydrogen evolution reaction that rises slowly $(-0.65$ to $-0.75 \mathrm{~V})$ and then rises rapidly beyond the cathodic polarization potential of $-0.75 \mathrm{~V}$ 

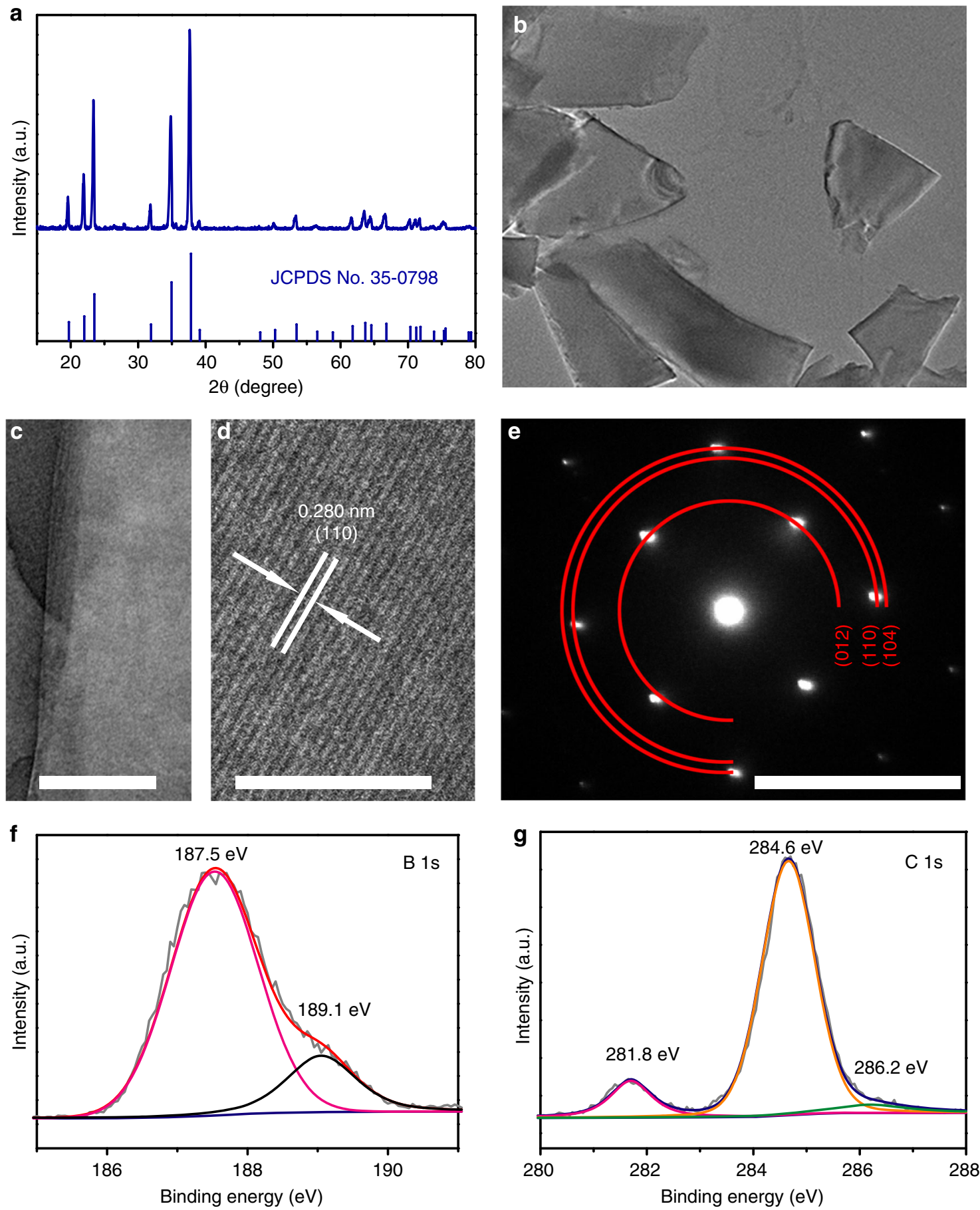

Fig. 1 Structure, morphology, and composition characterizations. a X-ray diffraction (XRD) pattern for $B_{4} C$. b, $\mathbf{c}$ Transmisson electron microscopy (TEM) micrograph (b) and further magnified TEM images (c) for $\mathrm{B}_{4} \mathrm{C}$ nanosheets. d, e High-resolution TEM image (d) and selected area electron diffraction (SAED) pattern for one $B_{4} C$ nanosheet (e). Scale bars, b $1 \mu \mathrm{m} ; \mathbf{c} 300 \mathrm{~nm} ; \mathbf{d} 5 \mathrm{~nm} ; \mathbf{e ~} 5 \mathrm{~nm}^{-1}$. f, $\mathbf{g}$ X-ray photoelectric spectra of $B_{4} C$ nanosheets in the $B 1 s$ (f) and $\mathrm{C}$ 1s (g) regions

(Supplementary Fig. 5) ${ }^{49}$. Of note, $\mathrm{N}_{2} \mathrm{H}_{4}$ was not detected, indicating this catalyst possesses excellent selectivity for $\mathrm{NH}_{3}$ formation (Supplementary Fig. 6). It is also important to mention that bare CPE has poor electrocatalytic NRR activity (Fig. 2d), revealing that the $\mathrm{B}_{4} \mathrm{C}$ nanosheet is highly active to catalyze $\mathrm{N}_{2}$ electroreduction.

To verify that the detected $\mathrm{NH}_{3}$ molecules mainly originate from the electrocatalyzed conversion of $\mathrm{N}_{2}$ by $\mathrm{B}_{4} \mathrm{C} / \mathrm{CPE}$, control experiments were carried out with an Ar-saturated electrolyte as a function of applied potential and with no potential applied to the electrodes under $\mathrm{N}_{2}$ gas (open circuit voltage). The corresponding UV-Vis absorption spectra (Supplementary Fig. 7) and calculated $\mathrm{NH}_{3}$ yields (Fig. 2c) show the presence of a tiny amount of $\mathrm{NH}_{3}$ that may come from sources of contamination (e.g., laboratory, equipment, membrane). A ${ }^{15} \mathrm{~N}$ isotopic labeling experiment was also performed to verify the $\mathrm{N}$ source of the produced $\mathrm{NH}_{3}$. As shown in Supplementary Fig. 8, the standard samples show a triplet coupling for ${ }^{14} \mathrm{NH}_{4}{ }^{+}$and a doublet coupling for ${ }^{15} \mathrm{NH}_{4}{ }^{+}$ 
in the ${ }^{1} \mathrm{H}$ nuclear magnetic resonance $\left({ }^{1} \mathrm{H}\right.$ NMR) spectra, and the use of ${ }^{14} \mathrm{~N}_{2}$ and ${ }^{15} \mathrm{~N}_{2}$ as the feeding gas yields ${ }^{14} \mathrm{NH}_{4}{ }^{+}$and ${ }^{15} \mathrm{NH}_{4}{ }^{+}$, repsectively. These results provide another piece of evidence to strongly support that $\mathrm{NH}_{3}$ was produced by $\mathrm{B}_{4} \mathrm{C}$ catalyzed electroreduction of $\mathrm{N}_{2}$.

Stability is also a critical parameter of NRR performance for practical applications. Under sustained $\mathrm{N}_{2}$ gas flow, 30-h electrolysis at a potential of $-0.75 \mathrm{~V}$ only leads to a slight decrease in current density (Fig. 3a). After long-term electrolysis, the $\mathrm{NH}_{3}$ yield for $\mathrm{B}_{4} \mathrm{C} / \mathrm{CPE}$ shows only $8 \%$ decrease compared with the initial one (Supplementary Fig. 9). Furthermore, $\mathrm{B}_{4} \mathrm{C} /$ CPE presents small changes in $\mathrm{NH}_{3}$ yield and $\mathrm{FE}$ during consecutive recycling tests at $-0.75 \mathrm{~V}$ for 7 times (Fig. 3b), indicating that high electrocatalytic activity for NRR is maintained very well. The TEM image of a $\mathrm{B}_{4} \mathrm{C}$ nanosheet after longterm electrocatalysis (Supplementary Fig. 10) shows almost no obvious change in morphology. XRD analysis (Supplementary Fig. 11) and XPS spectra (Supplementary Fig. 12) confirm that this catalyst is still $\mathrm{B}_{4} \mathrm{C}$ in nature after NRR. All these results indicate that this catalyst is robust enough to afford NRR electrocatalysis, which may be attributed to the excellent chemical and electrochemical stability of $\mathrm{B}_{4} \mathrm{C}$ in acid and its intrinsic high mechanical strength ${ }^{42}$.

The NRR activity of $\mathrm{B}_{4} \mathrm{C} / \mathrm{CPE}$ was also assessed in neutral media $\left(0.1 \mathrm{M} \mathrm{Na}_{2} \mathrm{SO}_{4}\right)$. Production of $\mathrm{NH}_{3}$ and the possible byproduct $\left(\mathrm{N}_{2} \mathrm{H}_{4}\right)$ were evaluated by a spectrophotometry method $^{31,48}$. The calibration curves are shown in Supplementary Fig. 13-14. $\mathrm{B}_{4} \mathrm{C} / \mathrm{CPE}$ still exhibits excellent selectivity without $\mathrm{N}_{2} \mathrm{H}_{4}$ production (Supplementary Fig. 15). As shown in

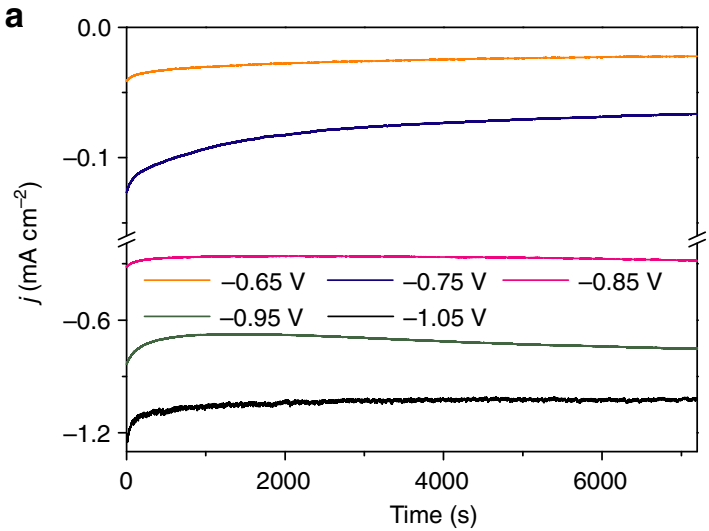

C

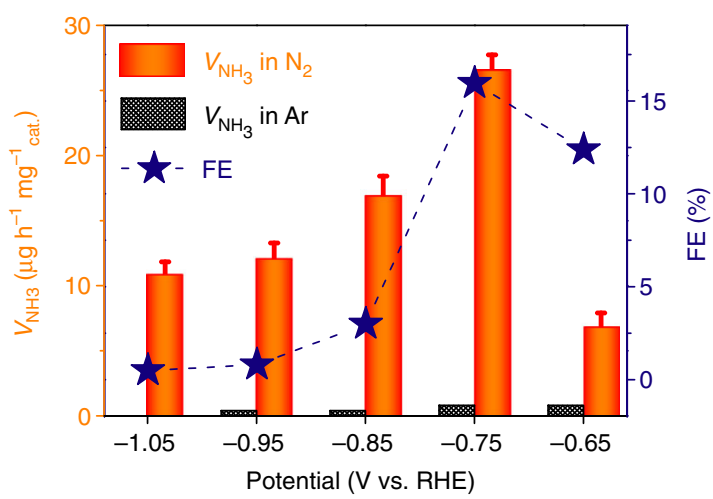

Supplementary Fig. 16-17, the $\mathrm{NH}_{3}$ yield can reach the highest value of $14.70 \mu \mathrm{g} \mathrm{h}^{-1} \mathrm{mg}^{-1}$ cat. with a FE of $9.24 \%$ at potential of $-0.75 \mathrm{~V}$. Time-dependent current density curves of $\mathrm{B}_{4} \mathrm{C} / \mathrm{CPE}$ for NRR at different potentials suggest excellent stability (Supplementary Fig. 18).

\section{Discussion}

To identify the active site and atomistic electrocatalytic processes of the NRR on the $\mathrm{B}_{4} \mathrm{C}$ surface, we used the exchange-correlation functional of Perdew, Burke, and Ernzerhof and the dispersion correction method of Grimme (PBE-D) in the framework of DFT to simulate the corresponding electrocatalytic reactions on the $\mathrm{B}_{4} \mathrm{C}$ (110) surface using a periodic slab model (see Methods for details). It is well known that the $\mathrm{N}_{2}$ adsorption on the catalyst surface is the first step to initialize the NRR and its initial adsorption configuration plays a vital role for subsequent catalytic reactions. Thus, we have first examined the $\mathrm{N}_{2}$ adsorption on the $\mathrm{B}_{4} \mathrm{C}(110)$ surface.

There are two main configurations available for the $\mathrm{N}_{2}$ adsorption on the $\mathrm{B}_{4} \mathrm{C}(110)$ surface. In the end-on configuration, only one terminal $\mathrm{N}$ atom is bonded to the $\mathrm{B}$ atom on the $\mathrm{B}_{4} \mathrm{C}$ (110) surface; in the side-on configuration, two terminal $\mathrm{N}$ atoms are separately bonded to two vertical B atoms that are located on two adjacent boron clusters (Supplementary Fig. 19). The $\mathrm{N}_{2}$ adsorption potential energies in these two structures are calculated to be $0.65 \mathrm{eV}$ and $0.63 \mathrm{eV}$ at the PBE-D level (free energies: $0.41 \mathrm{eV}$ and $0.34 \mathrm{eV}$, Supplementary Table 2). Since both configurations have similar energy profiles for the electrochemical $\mathrm{N}_{2}$ fixation reaction on the $\mathrm{B}_{4} \mathrm{C}(110)$ surface, in the following, we

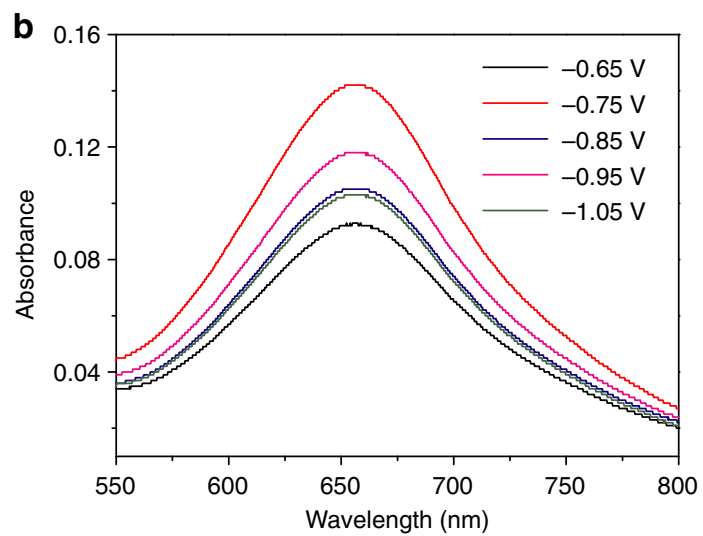

d

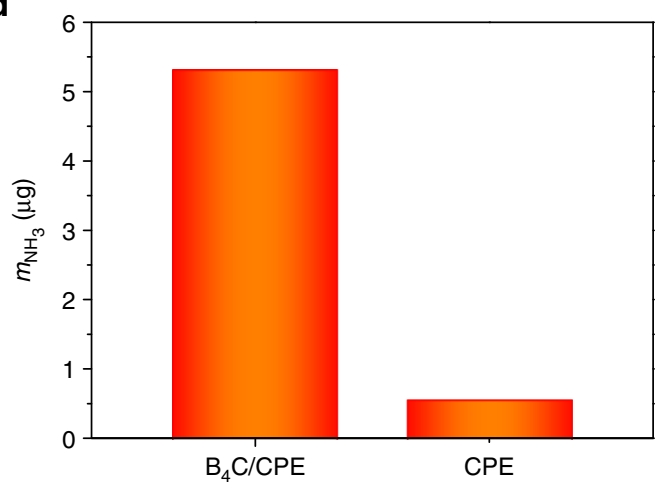

Fig. 2 Electrocatalytic nitrogen reduction performance. a Chrono-amperometry curves at various potentials in $\mathrm{N}_{2}$-saturated $0.1 \mathrm{M} \mathrm{HCl}$. b Ultraviolet-visible (UV-Vis) absorption spectra of the $0.1 \mathrm{M} \mathrm{HCl}$ electrolytes stained with indophenol indicator after electrolysis at a series of potentials for $2 \mathrm{~h}$ ( $7200 \mathrm{~s}$ ). $\mathbf{c}$ $\mathrm{NH}_{3}$ yields and Faradaic efficiencies (FEs) at each given potential in $0.1 \mathrm{M} \mathrm{HCl}$. d Amounts of $\mathrm{NH}_{3}$ generated with a carbon paper electrode (CPE) and a $\mathrm{B}_{4} \mathrm{C} / \mathrm{CPE}$ electrode after 2 -h electrolysis at potential of $-0.75 \mathrm{~V}$ under ambient conditions 

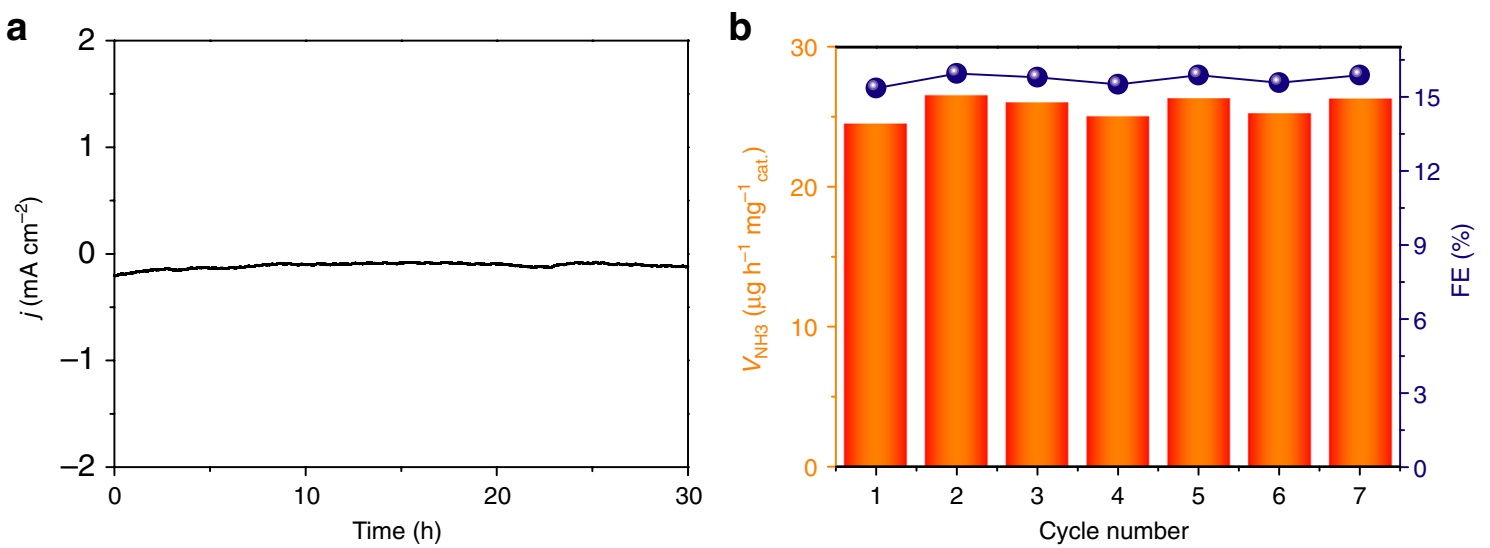

Fig. 3 Durability tests. a Time-dependent current density curve and (b) recycling test of $\mathrm{B}_{4} \mathrm{C} /$ carbon paper electrode $(\mathrm{CPE})$ at a potential of $-0.75 \mathrm{~V}$ under ambient conditions

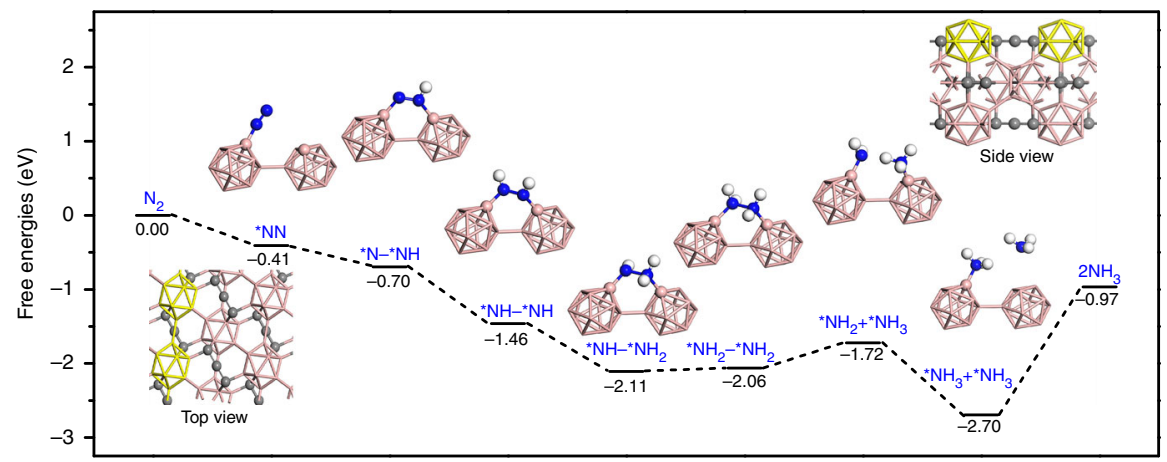

Fig. 4 Density functional theory calculations. Density functional theory (DFT) of Perdew, Burke, and Ernzerhof with the dispersion correction method of Grimme (PBE-D) calculated energy profiles for the electrocatalytic $\mathrm{N}_{2}$ fixation reaction on the $\mathrm{B}_{4} \mathrm{C}(110)$ surface starting from the end-on adsorption structure (see optimized structures in Supplementary Fig. 20; energy profiles from the side-on adsorption structure in Supplementary Fig. 22). Color code: blue, $\mathrm{N}$; rose, $\mathrm{B}$; gray, $\mathrm{C}$; white, $\mathrm{H}$; the asterisk * denotes an adsorption site

have merely focused on discussing the one starting from the endon configuration.

Figure 4 shows our DFT computed energy profiles for the electrocatalytic NRR processes on the $\mathrm{B}_{4} \mathrm{C}$ (110) surface starting from the end-on adsorption structure (optimized structures, Supplementary Fig. 20). The initial adsorption of molecular nitrogen in this end-on configuration releases $0.41 \mathrm{eV}$ free energy. It can be found that the reaction process from the adsorbed ${ }^{\star} \mathrm{NN}$ to ${ }^{\star} \mathrm{NH}-{ }^{\star} \mathrm{NH}_{2}$ species is completely barrierless and releases $1.70 \mathrm{eV}$ free energy at potential of $0.00 \mathrm{~V}$. The following reaction step, i.e., ${ }^{\star} \mathrm{NH}-{ }^{*} \mathrm{NH}_{2} \rightarrow{ }^{*} \mathrm{NH}_{2}{ }^{*}{ }^{\star} \mathrm{NH}_{2}$, is also facile because of a small energy gap of $0.05 \mathrm{eV}$ (PBE-D level). Different from the situation of other electrocatalyts, the rate-limiting step of the $\mathrm{NRR}$ on the $\mathrm{B}_{4} \mathrm{C}$ (110) surface corresponds to the ${ }^{*} \mathrm{NH}_{2}$ ${ }^{\star} \mathrm{NH}_{2} \rightarrow{ }^{\star} \mathrm{NH}_{2}+{ }^{\star} \mathrm{NH}_{3}$ reaction, which needs to overcome a barrier of $0.34 \mathrm{eV}$ at potential of $0.00 \mathrm{~V}$ (i.e., from -2.06 to $-1.72 \mathrm{eV}$ ). The final electrocatalytic addition reaction of a proton and electron pair on the adsorbed ${ }^{*} \mathrm{NH}_{2}$ species is barrierless. By contrast, the desorption of the $\mathrm{NH}_{3}$ molecule, i.e. ${ }^{*} \mathrm{NH}_{3} \rightarrow \mathrm{NH}_{3}$, demands $1.73 \mathrm{eV}$ free energy. Nevertheless, such a process remains energetically efficient concerning a lot of accumulated free energy in previous reaction processes $(2.70 \mathrm{eV}$ at potential of 0.00 V; see Fig. 4). Further discussion on the limiting potential of the NRR and the associated energy profile (Supplementary Fig. 21) can be found in Supplementary information. Finally, the energy profiles for the electrocatalytic processes starting from the side-on adsorption structure are similar to those from the end-on one (Supplementary Fig. 22).

In summary, a $\mathrm{B}_{4} \mathrm{C}$ nanosheet has been experimentally proven as a superior metal-free electrocatalyst for artificial $\mathrm{N}_{2}$ fixation to $\mathrm{NH}_{3}$ with excellent selectivity at room temperature and ambient pressure. This catalyst achieves a high $\mathrm{NH}_{3}$ yield of $26.57 \mu \mathrm{g} \mathrm{h}^{-1} \mathrm{mg}^{-1}$ cat. and a high $\mathrm{FE}$ of $15.95 \%$ at a potential of $-0.75 \mathrm{~V}$ in $0.1 \mathrm{M} \mathrm{HCl}$, with high electrochemical stability. Impressively, $\mathrm{B}_{4} \mathrm{C} / \mathrm{CPE}$ still exhibits good NRR activity in neutral media. Further DFT calculations reveal that the ${ }^{*} \mathrm{NH}_{2}{ }^{-} \mathrm{NH}_{2} \rightarrow{ }^{*} \mathrm{NH}_{2}{ }^{*} \mathrm{NH}_{3}$ reaction is the rate-limiting step. This study not only provides an attractive metal-free electrocatalyst material for $\mathrm{NH}_{3}$ synthesis, but also opens up an exciting new avenue to the rational design of $\mathrm{B}_{4} \mathrm{C}$-based nanocatalysts with enhanced performance for $\mathrm{N}_{2}$-fixation applications.

\section{Methods}

Sample preparation. Commercial bulk $\mathrm{B}_{4} \mathrm{C}$ was purchased from Aladdin Ltd. (Shanghai, China). All reagents were analytical reagent grade without further purification. The water used throughout all experiments was purified through a Millipore system. A total of $1 \mathrm{~g}$ bulk $\mathrm{B}_{4} \mathrm{C}$ was dispersed in $10 \mathrm{~mL}$ ethanol and stripped by ultrasonic cell disruptor for $1 \mathrm{~h}$. Subsequently, the resulting dispersion was centrifuged for $10 \mathrm{~min}$ at $3000 \mathrm{rpm}$ and the supernatant containing $\mathrm{B}_{4} \mathrm{C}$ nanosheet was decanted gently. Next, $710 \mu \mathrm{L}$ of the obtained solution was added 
into $250 \mu \mathrm{L} \mathrm{H} \mathrm{H}_{2} \mathrm{O}$ containing $40 \mu \mathrm{L}$ of $5 \mathrm{wt} \%$ Nafion and sonicated for $1 \mathrm{~h}$ to form a homogeneous ink. Then, $50 \mu \mathrm{L}$ of the dispersion was loaded onto a carbon paper electrode with area of $1 \times 1 \mathrm{~cm}^{2}$ and dried under ambient conditions, the catalyst loading mass is $0.1 \mathrm{mg} \mathrm{cm}^{-2}$.

Characterization. XRD pattern was recorded using a LabX XRD-6100 X-ray diffractometer, with a $\mathrm{Cu} \mathrm{Ka}$ radiation $(40 \mathrm{kV}, 30 \mathrm{~mA})$ of wavelength $0.154 \mathrm{~nm}$ (SHIMADZU, Japan). The structures of the samples were determined by TEM images on a HITACHI H-8100 electron microscopy (Hitachi, Tokyo, Japan) operated at $200 \mathrm{kV}$. SEM image was obtained on a Hitachi S- 4800 field emission scanning electron microscope at an accelerating voltage of $20 \mathrm{kV}$. XPS measurements were performed on an ESCALABMK II X-ray photoelectron spectrometer using $\mathrm{Mg}$ as the exciting source. The absorbance data of spectrophotometer were measured on SHIMADZU UV-1800 UV-Vis spectrophotometer. A gas chromatograph (SHIMADZU, GC-2014C) equipped with MolSieve 5A column and Ar carrier gas was used for $\mathrm{H}_{2}$ quantifications. Gas-phase product was sampled every $1000 \mathrm{~s}$ using a gas-tight syringe (Hamilton). ${ }^{1} \mathrm{H}$ NMR spectra were collected on a superconducting-magnet NMR spectrometer (Bruker AVANCE III HD $500 \mathrm{MHz}$ ) and dimethyl sulphoxide was used as an internal to calibrate the chemical shifts in the spectra.

Electrocatalytic nitrogen reduction measurements. The reduction of $\mathrm{N}_{2}$ gas (99.99\%) was carried out in a two-compartment cell under ambient condition, which was separated by Nafion 211 membrane. The membrane was protonated by first boiling in ultrapure water for $1 \mathrm{~h}$ and treating in $\mathrm{H}_{2} \mathrm{O}_{2}(5 \%)$ aqueous solution at $80^{\circ} \mathrm{C}$ for another $1 \mathrm{~h}$, respectively. And then, the membrane was treaded in $0.5 \mathrm{M} \mathrm{H}_{2} \mathrm{SO}_{4}$ for $3 \mathrm{~h}$ at $80^{\circ} \mathrm{C}$ and finally in water for $6 \mathrm{~h}$. The electrochemical experiments were carried out with an electrochemical workstation (CHI 660E). The potentials reported in this work were converted to reversible hydrogen electrode (RHE) scale via calibration with the following equation: $\mathrm{E}$ (vs. $\mathrm{RHE})=\mathrm{E}$ (vs. $\mathrm{Ag} /$ $\mathrm{AgCl})+0.256 \mathrm{~V}$ and the presented current density was normalized to the geometric surface area. For electrochemical $\mathrm{N}_{2}$ reduction, chrono-amperometry tests were conducted in $\mathrm{N}_{2}$-saturated $0.1 \mathrm{M} \mathrm{HCl}$ solution (the $\mathrm{HCl}$ electrolyte was purged with $\mathrm{N}_{2}$ for 30 min before the measurement).

Quantification of ammonia. When tested in $0.1 \mathrm{M} \mathrm{HCl}$, the concentration of $\mathrm{NH}_{3}$ produced was spectrophotometrically determined by the indophenol blue method ${ }^{7}$. Typically, $2 \mathrm{~mL} \mathrm{HCl}$ electrolyte was taken from the cathodic chamber, and then $2 \mathrm{~mL}$ of $1 \mathrm{M} \mathrm{NaOH}$ solution containing 5\% salicylic acid and 5\% sodium citrate was added into this solution. Subsequently, $1 \mathrm{~mL}$ of $0.05 \mathrm{M} \mathrm{NaClO}$ and $0.2 \mathrm{~mL}$ of $1 \% \mathrm{C}_{5} \mathrm{FeN}_{6} \mathrm{Na}_{2} \mathrm{O} \cdot 2 \mathrm{H}_{2} \mathrm{O}$ were add into the above solution. After standing at room temperature for $2 \mathrm{~h}$, the UV-Vis absorption spectrum was measured at a wavelength of $655 \mathrm{~nm}$. The concentration-absorbance curves were calibrated using standard $\mathrm{NH}_{3}$ solution (Supplementary Fig. 3) with a series of concentrations. The fitting curve $\left(y=1.130 x+0.078, R^{2}=0.999\right)$ shows good linear relation of absorbance value with $\mathrm{NH}_{3}$ concentration by three times independent calibrations. When tested in $0.1 \mathrm{M} \mathrm{Na}_{2} \mathrm{SO}_{4}$, the $\mathrm{NH}_{3}$ concentration was measured by a spectrophotometry method ${ }^{31}$. In detail, $4 \mathrm{~mL}$ of post-tested solution was removed from the cathodic chamber. Then, $50 \mu \mathrm{L}$ of oxidizing solution $\left(\mathrm{NaClO}\left(\rho_{\mathrm{Cl}}=\sim 4-4.9\right)\right.$ and $0.75 \mathrm{M} \mathrm{NaOH}), 500 \mu \mathrm{L}$ of coloring solution $\left(0.4 \mathrm{M} \mathrm{C}_{7} \mathrm{H}_{5} \mathrm{O}_{3} \mathrm{Na}\right.$ and $0.32 \mathrm{M}$ $\mathrm{NaOH})$ and $50 \mu \mathrm{L}$ of catalyst solution $\left(0.1 \mathrm{~g} \mathrm{Na}_{2}\left[\mathrm{Fe}(\mathrm{CN})_{5} \mathrm{NO}\right] 2 \mathrm{H}_{2} \mathrm{O}\right.$ diluted to $10 \mathrm{~mL}$ with deionized water) were added sequentially to the sample solution. After standing at $25^{\circ} \mathrm{C}$ for $1 \mathrm{~h}$, the UV-Vis absorption spectra were performed. The concentration of indophenol blue was determined using the absorbance at a wavelength of $655 \mathrm{~nm}$. The concentration-absorbance curve was calibrated using standard $\mathrm{NH}_{3}$ solution with a series of concentrations. The fitting curve ( $y=$ $0.753 x+0.026, R^{2}=0.999$ ) shows good linear relation of absorbance value with $\mathrm{NH}_{3}$ concentration by three times independent calibrations (Supplementary Fig. 13).

Quantification of hydrazine. The amount of $\mathrm{N}_{2} \mathrm{H}_{4}$ present in the electrolyte was estimated by the method of Watt and Chrisp ${ }^{48}$. A mixed solution of $5.99 \mathrm{~g}$ $\mathrm{C}_{9} \mathrm{H}_{11} \mathrm{NO}, 30 \mathrm{~mL} \mathrm{HCl}$, and $300 \mathrm{~mL}$ ethanol was used as a color reagent. Calibration curve was plotted as follow: first, preparing a series of standard solutions; second, adding $5 \mathrm{~mL}$ above prepared color reagent and stirring $20 \mathrm{~min}$ at room temperature; finally, the absorbance of the resulting solution was measured at $455 \mathrm{~nm}$, and the yields of $\mathrm{N}_{2} \mathrm{H}_{4}$ were estimated from a standard curve using $5 \mathrm{~mL}$ residual electrolyte and $5 \mathrm{~mL}$ color reagent. Absolute calibration of this method was achieved using $\mathrm{N}_{2} \mathrm{H}_{4}$ solutions of known concentration as standards, and the fitting curve shows good linear relation of absorbance with $\mathrm{N}_{2} \mathrm{H}_{4}$ concentration in $0.1 \mathrm{M} \mathrm{HCl}$ (Supplementary Fig. $4, y=0.545 x+0.031, R^{2}=0.999$ ) and $0.1 \mathrm{M} \mathrm{N}_{2} \mathrm{SO}_{4}$ (Supplementary Fig. 14, $\left.y=1.199 x+0.051, R^{2}=0.999\right)$ by three times independent calibrations.

Calculation of the Faradaic efficiency and yield. The FE for $\mathrm{N}_{2}$ reduction was defined as the amount of electric charge used for synthesizing $\mathrm{NH}_{3}$ divided the total charge passed through the electrodes during the electrolysis. The total amount of $\mathrm{NH}_{3}$ produced was measured using colorimetric methods. Assuming three electrons were needed to produce one $\mathrm{NH}_{3}$ molecule, the $\mathrm{FE}$ could be calculated as follows:

$$
\mathrm{FE}=\frac{3 \times \mathrm{F} \times \mathrm{C}_{\mathrm{NH}_{3}} \times \mathrm{V}}{17 \times \mathrm{Q}} .
$$

The rate of $\mathrm{NH}_{3}$ formation $\left(v_{\mathrm{NH}_{3}}\right)$ was calculated using the following equation:

$$
v_{\mathrm{NH}_{3}}=\frac{\mathrm{C}_{\mathrm{NH}_{3}} \times \mathrm{V}}{t \times m_{\text {cat. }}} \text {. }
$$

where $F$ is the Faraday constant, $\mathrm{C}_{\mathrm{NH}_{3}}$ is the measured $\mathrm{NH}_{3}$ concentration, $V$ is the volume of the $\mathrm{HCl}$ electrolyte for $\mathrm{NH}_{3}$ collection, $t$ is the reduction time and $m_{\text {cat }}$ is the catalyst loading mass.

FE for $\mathrm{H}_{2}$ was calculated according to following equation:

$$
\mathrm{FE}=2 \times \mathrm{F} \times n / \mathrm{Q},
$$

where $\mathrm{F}$ is the Faraday constant; $n$ is the actually produced $\mathrm{H}_{2}$ (mol), and Q is the quantity of applied electricity.

Calculation details. All DFT calculations are performed using the $\mathrm{DMol}^{3}$ module implemented in the Material Studio 8.0 package ${ }^{50,51}$. The generalized gradient approximation (GGA) with the PBE exchange-correlation functional is

employed $^{52}$. The empirical dispersion correction proposed by Grimme is used to consider weak van der Waals interaction ${ }^{53}$. The build-in double numerical plus polarization (DNP) basis set is used to expand the electronic wavefunction. A Monkhorst-Pack k-point grids of $2 \times 1 \times 1$ are used (see Supplementary Table 3 for benchmark). Self-consistent field (SCF) calculations are performed with a convergence criterion of $10^{-6}$ au on the total energy and electronic computations. Since the bulk water layer only slightly stabilizes the NRR intermediates ${ }^{54}$, we have therefore adopted the conductor-like screening model (COSMO) to simulate solvent effects ${ }^{55}$.

A three-layer $1 \times 2$ periodic slab model is used to represent the $\mathrm{B}_{4} \mathrm{C}(110)$ surface that is observed in our HRTEM image (see Supplementary Table 4 for benchmark). A $15 \AA$ vacuum layer is used between the two neighboring slabs to avoid artificial interaction. In geometric optimizations, all atoms except those in the bottom layer are fully relaxed. The adsorption energy $\left(\mathrm{E}_{\mathrm{ads}}\right)$ of species on the $\mathrm{B}_{4} \mathrm{C}(110)$ surface is defined as:

$$
\mathrm{E}_{\mathrm{ads}}=\mathrm{E}_{\mathrm{slab}}+\mathrm{E}_{\mathrm{mol}}-\mathrm{E}_{\mathrm{slab} / \mathrm{mol}}
$$

where $E_{\text {slab }}$ and $E_{m o l}$ are the energies of the isolated slab and species, respectively; and $E_{\text {slab/mol }}$ is the energy of the species-adsorbed slab system. The NRR process includes six net coupled proton and electron transfer (CPET) steps $\left(\mathrm{N}_{2}+6 \mathrm{H}^{+}\right.$ $+6 \mathrm{e}^{-} \rightarrow 2 \mathrm{NH}_{3}$ ). Based on previous theoretical studies ${ }^{54}$, gaseous hydrogen is used as the source of protons to simulate the reaction at the anode, i.e., $\mathrm{H}_{2} \leftrightarrow 2 \mathrm{H}$ $++2 \mathrm{e}^{-}$. Each CPET step includes the transfer of a proton coupled with an electron from solution to an adsorbed species on the $\mathrm{B}_{4} \mathrm{C}(110)$ surface. For each fundamental step, the Gibbs free energy change $(\Delta G)$ is calculated based on the standard hydrogen electrode (SHE) model proposed by Nørskov et al. ${ }^{56-58}$ in which the chemical potential of a proton-coupled-electron pair i.e., $\mu\left(\mathrm{H}^{+}\right)+\mu(\mathrm{e}$ $\left.{ }^{-}\right)$is equal to half of the chemical potential of gaseous hydrogen i.e., $1 / 2 \mu\left(\mathrm{H}_{2}\right)$ at a potential of $0 \mathrm{~V}$. Accordingly, the $\Delta \mathrm{G}$ value can be obtained as follows:

$$
\Delta \mathrm{G}=\Delta \mathrm{E}+\Delta \mathrm{ZPE}-\mathrm{T} \Delta \mathrm{S}+\Delta \mathrm{G}_{\mathrm{U}}+\Delta \mathrm{G}_{\mathrm{pH}},
$$

where $\Delta \mathrm{E}$ is the electronic energy difference, $\triangle \mathrm{ZPE}$ is the change in zero-point energies, $T$ is the temperature $(T=298.15 \mathrm{~K})$, and $\Delta S$ is the change of entropy. $\Delta \mathrm{G}_{\mathrm{U}}$ is the free energy contribution connected to electrode potential $\mathrm{U} . \Delta \mathrm{G}_{\mathrm{pH}}$ is the $\mathrm{H}^{+}$free energy correction by the concentration. It is calculated through $\Delta \mathrm{G}_{\mathrm{pH}}=$ $2.303 \times k_{\mathrm{B}} \mathrm{T} \times \mathrm{pH}$ where $k_{\mathrm{B}}$ is the Boltzmann constant and the value of $\mathrm{pH}$ is assumed to be zero in this work. It can be found that the free energy change of each elementary step is increased as the $\mathrm{pH}$ value increases. The zero-point energies and entropies of the NRR species are determined from the vibrational frequencies in which only the adsorbed species' vibrational modes are computed explicitly and the $\mathrm{B}_{4} \mathrm{C}(110)$ surface is fixed. The entropies and vibrational frequencies of molecules in the gas phase are taken from the NIST database. [http://cccbdb.nist.gov/]

Data availability. The data described in this paper are available from the authors upon reasonable request.

Received: 19 April 2018 Accepted: 25 July 2018

Published online: 28 August 2018

\section{References}

1. Smil, V. Detonator of the population explosion. Nature 400, 415 (1999). 
2. Schlögl, R. Catalytic synthesis of ammonia-a "never-ending story"? Angew Chem. Int. Ed. 42, 2004-2008 (2003).

3. Rosca, V., Duca, M., DeGroot, M. T. \& Koper, M. T. M. Nitrogen cycle electrocatalysis. Chem. Rev. 109, 2209-2244 (2009).

4. Vegge, T. et al. Indirect hydrogen storage in metal ammines. In: Solid State Hydrogen Storage: Materials and Chemistry (British Welding Research Association, Cambridge, UK, 2008).

5. MacKay, B. A. \& Fryzuk, M. D. Dinitrogen coordination chemistry: on the biomimetic borderlands. Chem. Rev. 104, 385-401 (2004).

6. Kitano, M. et al. Ammonia synthesis using a stable electride as an electron donor and reversible hydrogen store. Nat. Chem. 4, 934-940 (2012).

7. Zhu, D., Zhang, L., Ruther, R. E. \& Hamers, R. J. Photo-illuminated diamond as a solid-state source of solvated electrons in water for nitrogen reduction. Nat. Mater. 12, 836-841 (2013).

8. Shima, T. et al. Dinitrogen cleavage and hydrogenation by a trinuclear titanium polyhydride complex. Science 340, 1549-1552 (2013).

9. MacLeod, K. C. \& Holland, P. L. Recent developments in the homogeneous reduction of dinitrogen by molybdenum and iron. Nat. Chem. 5, 559-565 (2013).

10. Čorić, I., Mercado, B. Q., Bill, E., Vinyard, D. J. \& Holland, P. L. Binding of dinitrogen to an iron-sulfur-carbon site. Nature 256, 96-99 (2015).

11. Brown, K. A. et al. Light-driven dinitrogen reduction catalyzed by a CdS: nitrogenase MoFe protein biohybrid. Science 352, 448-450 (2016).

12. Eizawa, A. et al. Remarkable catalytic activity of dinitrogen-bridged dimolybdenum complexes bearing NHC-based PCP-pincer ligands toward nitrogen fixation. Nat. Commun. 8, 14874 (2017).

13. Légaré, M.-A. et al. Nitrogen fixation andreduction at boron. Science 359, 896-900 (2018).

14. Smil, V. Global population and the nitrogen cycle. Sci. Am. 277, 76-81 (1997)

15. Jennings, J. R. Catalytic ammonia synthesis: fundamentals and practice. (Plenum Press, New York, 1991)

16. Aika, K. et al. Ammonia, catalysis and manufacture. (Springer-Verlag Berlin Heidelberg, New York, Dordrecht, 1995).

17. Leigh, G. J. Haber-bosch and other industrial processes. In: Catalysts for Nitrogen Fixation. (Kluwer Academic Publishers, 2004).

18. Nørskov, J., Chen, J., Miranda, R., Fitzsimmons, T. \& Stack, R. Sustainable ammonia synthesis, DOE roundtable report. (U.S. department of energy Office of Science, Washington, DC, 2016).

19. Tanaka, H., Nishibayashi, Y. \& Yoshizawa, K. Interplay between theory and experiment for ammonia synthesis catalyzed by transition metal complexes. Acc. Chem. Res. 49, 987-995 (2016).

20. Chan, M. K., Kim, J. \& Rees, D. The nitrogenase FeMo-cofactor and P-cluster pair: 2.2 A resolution structures. Science 260, 792-794 (1993).

21. Burgess, B. K. \& Lowe, D. J. Mechanism of molybdenum nitrogenase. Chem. Rev. 96, 2983-3012 (1996).

22. Shipman, M. A. \& Symes, M. D. Recent progress towards the electrosynthesis of ammonia from sustainable resources. Catal. Today 286, 57-68 (2017).

23. Kyriakou, V., Garagounis, I., Vasileiou, E., Vourros, A. \& Stoukides, M Progress in the electrochemical synthesis of ammonia. Catal. Today 286, 2-13 (2017).

24. van der Ham, C. J. M., Koper, M. T. M. \& Hetterscheid, D. G. H. Challenges in reduction of dinitrogen by proton and electron transfer. Chem. Soc. Rev. 43, 5183-5191 (2014).

25. Seh, Z. W. et al. Combining theory and experiment in electrocatalysis: insights into materials design. Science 355, eaad4998 (2017).

26. Guo, C., Ran, J., Vasileff, A. \& Qiao, S.-Z. Rational design of electrocatalysts and photo(electro)catalysts for nitrogen reduction to ammonia $\left(\mathrm{NH}_{3}\right)$ under ambient conditions. Energy Environ. Sci. 11, 45-56 (2018).

27. Shi, M. M. et al. Au sub-nanoclusters on $\mathrm{TiO}_{2}$ toward highly efficient and selective electrocatalyst for $\mathrm{N}_{2}$ conversion to $\mathrm{NH}_{3}$ at ambient conditions. $A d v$. Mater. 29, 1606550 (2017)

28. Bao, D. et al. Electrochemical reduction of $\mathrm{N}_{2}$ under ambient conditions for artificial $\mathrm{N}_{2}$ fixation and renewable energy storage using $\mathrm{N}_{2} / \mathrm{NH}_{3}$ cycle. $A d v$. Mater. 29, 1604799 (2017)

29. Kugler, K., Luhn, M., Schramm, J. A., Rahimi, K. \& Wessling, M. Galvanic deposition of $\mathrm{Rh}$ and $\mathrm{Ru}$ on randomly structured $\mathrm{Ti}$ felts for the electrochemical $\mathrm{NH}_{3}$ synthesis. Phys. Chem. Chem. Phys. 17, 3768-3782 (2015)

30. Liu, H.-m. et al. Surfactant-free atomically ultrathin rhodium nanosheets nanoassemblies for efficient nitrogen electroreduction. J. Mater. Chem. A 6, 3211-3217 (2018).

31. Chen, S. et al. Electrocatalytic synthesis of ammonia at room temperature and atmospheric pressure from water and nitrogen on a carbon-nanotube-based electrocatalyst. Angew. Chem. Int. Ed. 56, 2699-2703 (2017).

32. Liu, Q. et al. Ambient $\mathrm{N}_{2}$ fixation to $\mathrm{NH}_{3}$ electrocatalyzed by spinel $\mathrm{Fe}_{3} \mathrm{O}_{4}$ nanorod. Nanoscale, 10, 14386-14389 (2018).
33. Chen, G.-F. et al. Ammonia electrosynthesis with high selectivity under ambient conditions via a $\mathrm{Li}^{+}$incorporation strategy. J. Am. Chem. Soc. 139, 9771-9774 (2017)

34. Zhang, L. et al. Electrochemical ammonia synthesis via nitrogen reduction reaction on $\mathrm{MoS}_{2}$ catalyst: theoretical and experimental studies. Adv. Mater. 30, 1800191 (2018).

35. Yang, D., Chen, T. \& Wang, Z. Electrochemical reduction of aqueous nitrogen $\left(\mathrm{N}_{2}\right)$ at a low overpotential on (110)-oriented Mo nanofilm. J. Mater. Chem. A 5, 18967-18971 (2017).

36. Han, J. et al. $\mathrm{MoO}_{3}$ nanosheets for efficient electrocatalytic $\mathrm{N}_{2}$ fixation to $\mathrm{NH}_{3}$. J. Mater. Chem. A 6, 12974-12977 (2018)

37. Ren, $\mathrm{X}$. et al. Electrochemical $\mathrm{N}_{2}$ fixation to $\mathrm{NH}_{3}$ under ambient conditions: $\mathrm{Mo}_{2} \mathrm{~N}$ nanorod as a highly efficient and selective catalyst. Chem. Commun. $\mathbf{5 4}$ 8474-8477 (2018)

38. Lv, C. et al. An amorphous noble-metal-free electrocatalyst enables $\mathrm{N}_{2}$ fixation under ambient conditions. Angew. Chem. Int. Ed. 57, 6073-6076 (2018).

39. Liu, Y. et al. Facile ammonia synthesis from electrocatalytic $\mathrm{N}_{2}$ reduction under ambient conditions on $\mathrm{N}$-doped porous carbon. ACS Catal. 8, 1186-1191 (2018).

40. Minakshi, M. \& Blackford, M. G. Electrochemical characteristics of $\mathrm{B}_{4} \mathrm{C}$ or $\mathrm{BN}$ added $\mathrm{MnO}_{2}$ cathode material for alkaline batteries. Mater. Chem. Phys. 123 700-705 (2010).

41. Lv, H., Peng, T., Wu, P., Pan, M. \& Mu, S. Nano-boron carbide supported platinum catalysts with much enhanced methanol oxidation activity and $\mathrm{CO}$ tolerance. J. Mater. Chem. 22, 9155-9160 (2012).

42. $\mathrm{Mu}, \mathrm{S}$. et al. Nano-size boron carbide intercalated graphene as high performance catalyst supports and electrodes for PEM fuel cells. Carbon 103 449-456 (2016)

43. Song, $\mathrm{S}$. et al. $\mathrm{B}_{4} \mathrm{C}$ as a stable non-carbon-based oxygen electrode material for lithiumoxygen batteries. Nano Energy 33, 195-204 (2017).

44. Kou, Z., Guo, B., He, D., Zhang, J. \& Mu, S. Transforming two-dimensional boron carbide into boron and chlorine dual-doped carbon nanotubes by chlorination for efficient oxygen reduction. ACS Energy Lett. 3, 184-190 (2017).

45. Vineesh, T. V. et al. Bifunctional electrocatalytic activity of boron-doped graphene derived from boron carbide. Adv. Energy Mater. 5, 1500658 (2015).

46. Reddy, K. M., Liu, P., Hirata, A., Fujita, T. \& Chen, M. W. Atomic structure of amorphous shear bands in boron carbide. Nat. Commun. 4, 2483 (2013).

47. Zhou, F. et al. Electro-synthesis of ammonia from nitrogen at ambient temperature and pressure in ionic liquids. Energy Environ. Sci. 10, 2516-2520 (2017).

48. Watt, G. W. \& Chrisp, J. D. Spectrophotometric method for determination of hydrazine. Anal. Chem. 24, 2006-2008 (1952).

49. Oshikiri, T., Ueno, K. \& Misawa, H. Selective dinitrogen conversion to ammonia using water and visible light through plasmon-induced charge separation. Angew. Chem. Int. Ed. 55, 3942-3946 (2016).

50. Delley, B. An all-electron numerical method for solving the local density functional for polyatomic molecules. J. Chem. Phys. 92, 508-517 (1990).

51. Delley, B. From molecules to solids with the $\mathrm{DMol}^{3}$ approach. J. Chem. Phys. 113, 7756-7764 (2000)

52. Perdew, J. P., Burke, K. \& Ernzerhof, M. Generalized gradient approximation made simple. Phys. Rev. Lett. 77, 3865 (1996).

53. Grimme, S. Semiempirical GGA-type density functional constructed with a long-range dispersion correction. J. Comput. Chem. 27, 1787-1799 (2006).

54. Skúlason, E. et al. A theoretical evaluation of possible transition metal electrocatalysts for $\mathrm{N}_{2}$ reduction. Phys. Chem. Chem. Phys. 14, 1235-1245 (2012).

55. Klamt, A. \& Schüürmann, G. COSMO: a new approach to dielectric screening in solvents with explicit expressions for the screening energy and its gradient. J. Chem. Soc., Perkin Trans. 2 0, 799-805 (1993).

56. Nørskov, J. K., Rossmeisl, J., Logadottir, A. \& Lindqvist, L. Origin of the overpotential for oxygen reduction at a fuel-cell cathode. J. Phys. Chem. B 108, 17886-17892 (2004).

57. Rossmeisl, J., Logadottir, A. \& Nørskov, J. K. Electrolysis of water on (oxidized) metal surfaces. Chem. Phys. 319, 178-184 (2005).

58. Peterson, A. A., Abild-Pedersen, F., Studt, F., Rossmeisl, J. \& Nørskov, J. K. How copper catalyzes the electroreduction of carbon dioxide into hydrocarbon fuels. Energy Environ. Sci. 3, 1311-1315 (2010).

\section{Acknowledgements}

This work was supported by the National Natural Science Foundation of China (Nos. 21575137 and 21522302). We also appreciate Hui Wang from the Analytical and Testing Center of Sichuan University for her help with SEM characterization. 


\section{Author contributions}

X.S. developed the ideas and designed the experiments. X.S., G.C. and B.T. wrote the paper. W.Q., X.R. and X.J. carried out all experiments. X.X., W.F. and G.C. performed all computations. All authors discussed and analysed the data.

\section{Additional information}

Supplementary Information accompanies this paper at https://doi.org/10.1038/s41467018-05758-5.

Competing interests: The authors declare no competing interests.

Reprints and permission information is available online at http://npg.nature.com/ reprintsandpermissions/

Publisher's note: Springer Nature remains neutral with regard to jurisdictional claims in published maps and institutional affiliations (c) (i) Open Access This article is licensed under a Creative Commons Attribution 4.0 International License, which permits use, sharing, adaptation, distribution and reproduction in any medium or format, as long as you give appropriate credit to the original author(s) and the source, provide a link to the Creative Commons license, and indicate if changes were made. The images or other third party material in this article are included in the article's Creative Commons license, unless indicated otherwise in a credit line to the material. If material is not included in the article's Creative Commons license and your intended use is not permitted by statutory regulation or exceeds the permitted use, you will need to obtain permission directly from the copyright holder. To view a copy of this license, visit http://creativecommons.org/ licenses/by/4.0/.

(C) The Author(s) 2018 